Tjalling C. Koopmans Research Institute Tplligl Aoopman

Discussion Paper Series nr: 12-01

\title{
The Energy-GDP Nexus; Addressing an old question with new methods
}

\author{
R. J. Coers \\ M. Sanders
}




\section{Tjalling C. Koopmans Research Institute \\ Utrecht School of Economics \\ Utrecht University}

Kriekenpitplein 21-22

3584 EC Utrecht

The Netherlands

telephone +31302539800

fax +31302537373

website www.koopmansinstitute.uu.nl

The Tjalling C. Koopmans Institute is the research institute and research school of Utrecht School of Economics.

It was founded in 2003, and named after Professor Tjalling C. Koopmans, Dutch-born Nobel Prize laureate in economics of 1975.

In the discussion papers series the Koopmans Institute publishes results of ongoing research for early dissemination of research results, and to enhance discussion with colleagues.

Please send any comments and suggestions on the Koopmans institute, or this series to J.M.vanDort@uu.nl

ontwerp voorblad: WRIK Utrecht

\section{How to reach the authors}

Please direct all correspondence to the last author.

\section{R.J.Coers}

M. Sanders

Utrecht University

Utrecht School of Economics

Kriekenpitplein 21-22

3584 TC Utrecht

The Netherlands.

E-mail: M.W.J.L.Sanders@uu.nl 
Utrecht School of Economics

Tjalling C. Koopmans Research Institute

Discussion Paper Series 12-01

\title{
The Energy-GDP Nexus; Addressing an old question with new methods
}

\author{
R. J. Coers \\ M. Sanders \\ Utrecht School of Economics \\ Utrecht University \\ January 2012
}

\begin{abstract}
This paper reassesses the causal relationship between per capita energy use and gross domestic product, while controlling for capital and labour (productivity) inputs in a panel of 30 OECD countries over the past 40 years. The paper uses panel unit root and cointegration testing and specifies an appropriate vector error correction model to analyse the nexus between income and energy use. In doing so we contribute to an old debate using modern tools that shed a new light. There is some evidence that over the short-run bidirectional causality exists. Our results also show a strong unidirectional causality running from capital formation and GDP to energy usage. In the long run the reverse causality, found in recent work, is lost. We then show that we can reproduce these earlier results in our data if we reproduce a slightly misspecified model for the Engle-Granger two-step procedure used in these earlier papers. Our findings thus imply that results are very sensitive to model misspecification and careful testing of specifications is required. Our results have some strong policy implications. They suggest that policies aimed at reducing energy usage or promoting energy efficiency are not likely to have a detrimental effect on economic growth, except over the very short run.
\end{abstract}

Keywords: Energy; GDP; capital; labour; causality; cointegration.

JEL classification: C23; 010; Q40; Q43

\section{Acknowledgements}

The authors would like to thank Adriaan Kalwij and participants in the Tjalling Koopmans Institute research seminars for helpful comments on methodological parts of the research. The Utrecht University library staff is also gratefully acknowledge for assistance in the data collection. 


\section{Introduction}

Energy use and per capita GDP are highly correlated over time and space. This correlation has lent support to the claim of "resource economics" that energy is an essential input in the economy, but can also be explained by mainstream arguments that posit energy use is the result of higher income and high income elasticities on energy intensive products and services. Empirically the direction of causation is notoriously hard to establish and an ongoing debate has unfolded in the literature since the seminal article by Kraft and Kraft (1978). Due to rapid developments in econometrics much of the early work in this field was outdated before a consensus could be reached on the direction of the relationship. The answer to this question, however, is of growing importance, because the direction of causality has big implications for public policy in the fields of climate change and energy security. If energy can be shown to "cause" economic activity, then all efforts should be put in getting and maintaining access to a cheap but greener and safer energy supply. If energy use is found to be a consequence of economic activity and driven by growing incomes and demand, however, than the response should be to reduce energy demand using market based and regulatory instruments. Bidirectional causation and/or neutrality (no causation) would call for an appropriate mix of both approaches.

The question has and continues to attract the attention of many scholars in the field (see e.g. Mehrara (2007) and Stern (2000) for overviews of this debate). The contributions of this paper are that it will reassesses the causal relation between energy and income by means of a literature study and state of the art econometric analysis. The literature review serves to position the paper. Then we analyse a panel of 30 OECD countries over the time period between 1960 and 2000. Therein lies our first contribution as to our knowledge the issue has not been studied in a panel of such breath (30 countries) or length (40 years) to date. ${ }^{3}$ Between them these countries account for about 65 (1960) to 55 \% (2000) of world GDP and comparable percentages of global energy use and greenhouse gas emissions. ${ }^{4}$ Our second contribution comes from the fact that we employ appropriate state-of-the-art multivariate panel data cointegration techniques to assess the specific mechanism by which the causality between income and energy use runs. A final contribution follows when we show that a slightly misspecified error correction term causes our results to

\footnotetext{
3 Only in an unpublished working paper by Sinha (2009) did we find a panel of comparable dimensions (88 countries and 28 years), but that paper adds more diversity among countries, notably adding 58 developing countries, at the cost of losing the ability to control for capital as such data are lacking. We agree with Narayan and Smyth (2008) and Lee, Chang and Chen (2008) that not controlling for capital is a serious omission that can bias the results and we argue that the time dimension is much more relevant when we study the causal relationship between energy use and GDP. We therefore chose depth over breath and our sample contains longer time series on much more similar (OECD) countries.

4 See for example Energy Information Administration (2006)
} 
be overturned, explaining why our results differ from those in the few studies that have employed multivariate panel cointegration techniques (e.g. Mahadevan and Asafu-Adjaye (2007), Narayan and Smyth (2008), Lee, Chen and Chang (2008)) and stressing the importance of appropriate specification. Finally, we contrast our results to those in Sinha (2009) who analyses a much broader set of countries (including 58 developing countries) over a shorter time span without controlling for capital. We conclude that, with a correct model specification and controlling for capital intensity, GDP growth drives energy use in the long run ( $>2$ years) and not the other way around in the OECD. OECD countries should therefore not hesitate and implement energy demand reducing policies to achieve climate objectives and reduce energy dependency.

The remainder of the paper is structured as follows; section 2 starts with an overview of previous studies conducted in this field. Section 3 describes our data, introduces the methodology and presents the results of the empirical analysis, after which section 4 concludes.

\section{Literature review}

The topic of causality between energy use and economic growth has been under study for 30 years and scores of papers have been published on the topic. ${ }^{5}$ Despite these efforts, however, a consensus has not emerged. In this section we do not intend to be complete in our review of the literature, but rather discuss some selected publications that are representative for many others. Previous work by different authors can broadly be divided into four categories of results (no causation, causation from energy to GDP, causation from GDP to energy and bidirectional causation) and five categories of methodologies (Simple causality tests, Bivariate and Multivariate VECM, Bivariate and Multivariate Panel VECM). Table 1 gives an overview of some representative papers in this literature. First there are several publications finding unidirectional causality between energy and income, either from energy to income or vice versa. Second, the hypothesis of the 'neutrality' of energy to income has been confirmed using different methodologies. And finally, different authors have claimed bidirectional causality exists.

Following Mehrara (2007), these publications can also be divided into four 'generations'. The first generation (e.g. Kraft and Kraft (1978) and Yu and Hwang (1984)) of the literature used a 'traditional' VAR regression approach to infer causality

5 See Mehrara (2007) for an excellent overview. 
between the two series under study, assuming stationarity of the data under study. Analysis by means of this methodology was conducted from 1978 to the end of the 1980's. With the rise of stationarity testing and correction in econometrics the analysis evolved and measures were taken to account for the presence of unit roots in time series. Second-generation publications (e.g. Masih and Masih (1996) and Glasure and Lee (1997)) made use of error correction models (ECM) and cointegration to assess Granger (1988) causality in a bivariate framework. Making use of the new methodology, first generation studies where put aside as the regression results could be considered 'spurious'. Building upon this, the third generation (e.g. Asafu-Adjaye (2000) and Stern (2000)) used a multivariate ECM approach following Johansen's (1991) causality testing method to account for omitted variable bias, a critique by which second-generation studies are repeatedly refuted. This third generation framework allowed for a correction of other inputs into the production function, such as capital, labour, prices, etc. However, with such specifications, country and time specific effects were not taken into account. Therefore, a fourth generation literature (e.g. Lee (2005, 2006), Soytas and Sari (2003, 2006), Ghali and El-Sakka (2004) and Sinha (2009)) is published from approximately 2003 onwards and makes use of (bivariate) panel cointegration and panel error correction models to allow for these specific time and country dimension effects. Unfortunately none of the published studies in this generation to date have made use of the full benefits of large variation in data made possible by panel analysis. This is mainly caused by lack of data, which confines most panels to less than 10 members (most studies above have less than 20 countries and span at most 40 years). Notable exception is an unpublished working paper Sinha (2009) that has analysed 88 countries over 28 years.

In what we consider a fifth generation, papers start using the multivariate panel VECM tools to also control for capital-energy complementarities (e.g. Lee and Chang (2008), Lee, Chang and Chen (2008), Naryan and Smyth (2008)). These papers generally conclude that energy consumption Granger causes economic growth and income, where only Lee, Chang and Chen also find the reverse causation. This contrasts sharply with our finding that income (growth) and capital Granger cause energy use but not the other way around. We can trace this back to the specification of our error correction term and discuss these differences at some length in our results section. 


\begin{tabular}{|c|c|c|c|c|c|}
\hline Authors & Year & Method & Main Results & countries included in study & timespan \\
\hline Kraft \& Kraft & 1978 & Sims causality test & Income causes energy & USA & $1947-1974$ \\
\hline Yu \& Hwang & 1984 & Sims causality test & Neutral & USA & $1947-1979$ \\
\hline Yu \& Jin & 1992 & Bivariate cointegration model & Neutral & USA & $1974-1990$ \\
\hline Masih \& Masih & 1996 & Multivariate VECM & Different per country & Malaysia, Singapore, Philippines, & $1955-1990$ \\
\hline Glasure \& Lee & 1997 & Bivariate VECM & Bidirectional causality & South Korea, Singapore & $1961-1990$ \\
\hline Asafu-Adjaye & 2000 & Multivariate VECM & Different per country & India, Indonesia, Thailand, Philippines & $1972-1995$ \\
\hline Stern & 2000 & Multivariate VECM & Energy causes income & USA & $1948-1994$ \\
\hline Glasure & 2002 & Vector autoregression & Neutral & Korea & $1961-1990$ \\
\hline Soytas \& Sari & 2003 & Bivariate VECM & Different per country & G7 \& top 10 emerging markets & $1950-1992$ \\
\hline Ghali \& E1-Sakka & 2004 & Bivariate VECM & Bidirectional causality & Canada & $1961-1997$ \\
\hline Lee & 2005 & Bivariate panel VECM & Energy causes income & 18 developing countries & $1975-2001$ \\
\hline Soytas \& Sari & 2006 & Multivariate panel VECM & Different per country & G7 & $1960-2004$ \\
\hline Al-Iriani & 2006 & Bivariate panel VECM & Income causes energy & Gulf Cooperation Council & $1971-2002$ \\
\hline Mehrara & 2007 & Bivariate panel VECM & Income causes energy & 11 oil exporting countries & $1971-2002$ \\
\hline Mahadevan \& Asafu & 2007 & Multivariate panel VECM & Bidirectional causality & 20 developing/developed countries & $1971-2002$ \\
\hline Lee \& Chang & 2007 & Multivariate panel VECM & Energy causes income & 16 Asian countries & $1971-2002$ \\
\hline Narayan \& Smyth & 2008 & Multivariate panel VECM & $\begin{array}{l}\text { Energy and capital cause income } \\
\text { Bidirectional causality between }\end{array}$ & G7 & $1972-2002$ \\
\hline Lee, Chang \& Chen & 2008 & Multivariate panel VECM & capital, energy and growth & 22 OECD countries & $1960-2001$ \\
\hline
\end{tabular}

\section{Data, Methodology and Empirical Results}

We first collected a dataset on 30 OECD countries $^{6}$ for the period 1960-2000, containing GDP and Gross Fixed Capital Formation (GFCF) (OECD-STAN database), energy use ${ }^{7}$ (United Nations International Energy Agency's (IEA) Energy Statistics of OECD countries and Energy Balances of OECD and other IEA/OECD statistical databases), employment (OECD annual labour force statistics) and educational attainment of the workforce (World Bank, Barro and Lee (2001)). We follow Lee (2005) and Soytas \& Sari (2006) among others in taking GFCF as a proxy for the capital stock and use the multiple of labour and educational attainment as a proxy for human capital in the production function. Tables $A 1$ and $A 2$ in the appendix provide the descriptive statistics for our dataset over the country and time dimension.

We then use a multivariate panel approach based on panel cointegration and error correction techniques. To establish that this is econometrically appropriate, one needs to follow a clear 3-step procedure. First, all series have to be proven to be suitable for analysis by means of this framework. All data first have to be non-stationary and should not be integrated of order 1, I(1). Second, a long-term cointegrating relation needs to exist between the main variables in our model. After showing that our data

\footnotetext{
6 Australia, Austria, Belgium, Canada, Czech Republic*, Denmark, Finland, France, Germany, Greece, Hungary*, Iceland, Ireland, Italy, Japan, Korea*, Luxemburg, Mexico*, Netherlands, New Zealand, Norway, Poland, Portugal, Slovenia*, Spain, Sweden, Switzerland, Turkey, United Kingdom and United States. Asterisk signifies missing values, implying these countries were dropped in tests and regressions that require a balanced panel.

7 Data on Energy use, as found in the 'Energy Statistics of OECD Countries' dataset, have been used to compare different amounts of energy inputs in different countries. Using conversion factors, derived from the 'Energy Balances of OECD Countries', measures of total energy consumption (EC) where constructed on a per country per capita basis, thus taking into account differences in the 'quality' of different energy inputs such as oil, coal, gas, water, wind, etc.
} 
satisfy the requirements for using this method, we proceed to specify the model and present our results.

\subsection{Unit Root Tests}

To test the presence of unit roots in our data we present panel unit root tests for all series in table 2 below. Table 2 presents test statistics using methods developed by Levin, Lin and Chu (2002) (LCC), Im, Pesaran and Shin (2003) (IPS) and the Fisher test developed by Maddala and Wu (1999). The three tests mentioned above are constructed to test for non-stationarity in time series in a panel context as the (augmented) Dickey Fuller (1979) test can only be used for single time series. ${ }^{8}$ In the right columns the results for these tests with first differenced data are presented.

Table 2 unit root statistics

Unit Root Statistics of variables in levels

Unit Root Statistics of variables in first differences

\begin{tabular}{|c|c|c|c|c|c|c|c|c|}
\hline & LLC test & IPS test & Fisher test & & LLC test & IPS test & & Fisher test \\
\hline Variable & t-star & W/t-bar] & $x^{2}$ & Variable & t-star & W[t-bar] & & $x^{2}$ \\
\hline $\log (g d p p p p c a)$ & $-0.11[2][t]$ & $2.26[2][t]$ & $59.95[2][t]$ & $\Delta \log (g d p p p c a)$ & $-3.63[2][t]$ & $-7.87[2][t]$ & 14 & $156.78[2][t]$ \\
\hline $\log (e c c a)$ & $-1.57[2][t]$ * & $0.85[2][t]$ & $77.67[2][t]^{*}$ & $\Delta \log ($ ecca $)$ & $-2.43[2][t]$ & $-6.15[2][t]$ & 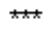 & $171.98[2][t]$ \\
\hline $\log (e m p)$ & $0.99[2][t]$ & $2.33[2][t]$ & $49.18[2][t]$ & $\Delta \log (\mathrm{emp})$ & $-4.19[2][t]$ & $-7.47[2][t]$ & 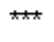 & $174.22[2][t]$ \\
\hline $\log (g f c f)$ & $-0.97[2]$ & $-1.00[2]$ & $38.22[2]$ & $\Delta \log (g f c f)$ & $-7.59[2]$ & $-11.7[2]$ & $\ldots$ & $318.74[2]$ \\
\hline $\log ($ school) & $-0.50[2][t]$ & $0.38[2][t]$ & $71.24[2][\mathrm{t}]$ & $\Delta \log ($ school $)$ & $-2.75[2][t]$ & $-3.97[2]$ & 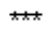 & $113.30[2]$ \\
\hline
\end{tabular}

H0: nonstationarity i unit root

Number between [..] is the amount of lags used, [t] is trend

* signals significance on a $10 \%$ level, ${ }^{* *} 5 \%$ and $* * * 1 \%$

Table 2 displays the results of the LLC, IPS and Fisher test for all 5 variables in our dataset. The results clearly show that all data are integrated of order 1 but not of order 2, suggesting a specification in first differences is appropriate to avoid spurious regression bias.

\subsection{Cointegration Test}

The LLC, IPS and Fisher test results imply we consider a first difference specification of the final model. In a Granger causality framework, it is also required to establish the presence of stationarity between different variables included in the analysis. To do so we test for cointegrating behaviour. This can be tested by means of the Westerlund

\footnotetext{
8 As all tests have their specific strengths and weaknesses, we will show results for all three. The LLC-test tests for the presence of unit root by assuming that each individual unit root in the panel shares the same AR(1) coefficient. This test is best viewed as a pooled (augmented) Dickey Fuller test, with a null hypothesis of non-stationarity. The IPS-test tests for the presence of unit root in a heterogeneous panel setting. Comparable to the LLC test it allows for individual as well as time effects and trends. Bute here the results are based on the mean of the individual Dickey Fuller $t-$ statistics of each individual series. Finally, the Fisher test 'combines the p-values from N independent unit root tests'. Based on the $p$-values of the individual unit root tests, the Fisher test assumes, comparable to the LLC and IPS test, that all series are I(1) under the null hypothesis of non-stationarity. It provides added insights because the data do not have to be balanced to come to consistent results, and it thus combines results for all members in the panel under analysis.
} 
(2006, 2007) framework for panel cointegration testing. ${ }^{9}$ Table 3 below presents the results of the Persyn and Westerlund (2008) panel cointegration tests performed in our data. All tests are between (log) energy consumption and the variables of interest, log GDP (LGDP), log Gross Fixed Capital Formation (LGFCF), log Employment (LEMP) and log Human Capital (LSCHOOL), where the latter is defined as the average years of education times the level of employment. First the co movement between log energy consumption (LEC) and log GDP is assessed, for which the Westerlund test provides clear evidence. All test statistics clearly reject the null hypothesis of no cointegration on a $1 \%$ significance value. This implies GDP and energy are cointegrated and GDP should be included in the error correction term.

Table 3 Panel cointegration statistics

\begin{tabular}{|c|c|c|c|c|}
\hline Covariates & \# Series & Statistic & Z-value & P-value \\
\hline LGDP & 31 & Gt & $-7,695$ & 0 \\
\hline LGDP & 31 & $\mathrm{Ga}$ & $-1,647$ & 0.05 \\
\hline LGDP & 31 & $\mathrm{Pt}$ & $-7,741$ & 0 \\
\hline LGDP & 31 & $\mathrm{~Pa}$ & $-5,26$ & 0 \\
\hline LGDP \& LGFCF & 31 & Gt & $-3,766$ & 0 \\
\hline LGDP \& LGFCF & 31 & $\mathrm{Ga}$ & $-3,440$ & 0 \\
\hline LGDP \& LGFCF & 31 & $\mathrm{Pt}$ & $-3,097$ & 0.001 \\
\hline LGDP \& LGFCF & 31 & $\mathrm{~Pa}$ & $-3,570$ & 0 \\
\hline LGDP, LGFCF \& LEMP & 25 & Gt & $-1,925$ & 0.027 \\
\hline LGDP, LGFCF \& LEMP & 25 & $\mathrm{Ga}$ & $-3,381$ & 0 \\
\hline LGDP, LGFCF \& LEMP & 25 & $\mathrm{Pt}$ & $-0,272$ & 0,393 \\
\hline LGDP, LGFCF \& LEMP & 25 & $\mathrm{~Pa}$ & $-0,681$ & 0,248 \\
\hline LGDP, LGFCF \& LSCHOOL & 30 & Gt & 0,304 & 0,620 \\
\hline LGDP, LGFCF \& LSCHOOL & 30 & $\mathrm{Ga}$ & $-0,249$ & 0,402 \\
\hline LGDP, LGFCF \& LSCHOOL & 30 & Pt & 0,187 & 0,574 \\
\hline LGDP, LGFCF \& LSCHOOL & 30 & $\mathrm{~Pa}$ & $-0,094$ & 0,463 \\
\hline
\end{tabular}

H0: no cointegration

* signals significance on a $10 \%$ level, ** $5 \%$ and *t* $1 \%$

Second, the co movement of (log) energy use, (log) gross fixed capital formation and (log) GDP is analysed. Again the evidence is strong with all four tests being significant at the $5 \%$, and 3 out of 4 at the $1 \%$ level. This implies that GFCF should also be included in the error correction term. Finally, the results for co movement between

\footnotetext{
9 Because 'normal' unit root tests (see e.g. LLC, IPS and Fisher methodology described above) based on the residual of the cointegration relationship do not take into account the effects of structural breaks, if present, the null (a unit root) can often not be rejected while there is actually no unit root present (type II error). The Westerlund test tests for the absence of cointegration by determining if there exist error corrections for individual panel members or for the panel as a whole. This is done under the assumption that all variables are non stationary or $\mathrm{I}(1)$ as we have established for our data in first differences above. The test presents four test statistics: Ga, Gt, Pa and Pt. The Ga and Gt statistics test for the null that all parameters of the lagged dependent variable on the right hand side are not significantly different for zero for all members in the panel versus the alternative that at least one parameter of the lagged dependent variable is significantly different from zero. They differ because they start from a weighted average of the individually estimated coefficients $(\mathrm{Ga})$, or their respective t-ratio's (Gt). The Pa and Pt test statistics pool all information over the cross-sectional dimension of the dataset to test the same hypothesis as above. The different statistics therefore, shed light on the rejection of the null that cointegration is present, under different assumptions.
} 
four vectors, including employment and/or human capital suggest these variables are not cointegrated with energy consumption and shall be used as general control variables in the regression framework outlined below. ${ }^{10}$ From these tests it can be concluded that the cointegration term in our model must be specified in terms of energy, capital and GDP, along the lines of Mehrara (2007). ${ }^{11}$

\subsection{Model specification}

Because cointegration is found, causality is best assessed using the Engle-Granger framework (Engle and Granger (1987), Granger (1988), Granger and Lin (1995)). We use a vector error correction model, or VECM, specification, which basically consists of a two-stage procedure. In the first stage of the regression analysis, we specify the cointegration relationship to assess the long-term co movement between energy, capital and output. This relation is regressed using the following specification:

$$
L E C_{i t}=\alpha_{i}+\delta_{i} t+\beta_{1} L G D P_{i t}+\beta_{2} L G F C F_{i t}+\varepsilon_{i t}
$$

The error correction term contains a country specific intercept, $a_{i}$, a time trend $\delta_{t}$, a coefficient quantifying the influence of GDP $\beta_{1}$, a coefficient for gross fixed capital investment, $\beta_{2}$ and an error term $\varepsilon_{i t}$.

Second, the residuals of (4) are used as a (lagged) regressor, $E C T=\varepsilon_{i t}$, in the final VECMs. To test for causality we need to estimate both a model with growth in energy consumption and growth in GDP as the dependent variable. On the left hand side we include the (lagged) ECT specified above and lags of the dependent variables and explanatory variables. Moreover, we control for the growth in human and physical capital in both regressions. The estimated models are thus given by:

Model A:

$$
\begin{aligned}
& \Delta L E C_{i t}=\alpha_{a i t}+\gamma_{a i} E C T_{i t-1}+\sum_{p} \beta_{a 1 i p} \Delta L E C_{i t-p} \\
& +\sum_{p} \beta_{a 2 i p} \Delta L G D P_{i t-p}+\sum_{p} \beta_{a 3 i p} \Delta L G F C F_{i t-p}+\sum_{p} \beta_{a 4 i p} \Delta L S C H O O L_{i t-p}+v_{i t}
\end{aligned}
$$

Model B:

$$
\begin{aligned}
& \Delta L G D P_{i t}=\alpha_{b i t}+\gamma_{b i} E C T_{i t-1}+\sum_{p} \beta_{b 1 i p} \Delta L E C_{i t-p} \\
& +\sum_{p} \beta_{b 2 i p} \Delta L G D P_{i t-p}+\sum_{p} \beta_{b 3 i p} \Delta L G F C F_{i t-p}+\sum_{p} \beta_{b 4 i p} \Delta L S C H O O L_{i t-p}+\psi_{i t}
\end{aligned}
$$


where subscripts $a$ and $b$ signal coefficients from the first or the latter model, subscripts $i$ and $t$ denote the country and time dimension of the regression and $\Delta$ signifies first differences. Subscript $p$ denotes the lag length used for the different explanatory variables, from $t-1$ to $t-p$, conditional on their significance. The coefficients labelled $\beta_{a, b 1 i p}$ to $\beta_{a, b 4 i p}$ quantify the relation between their respective (lagged) explanatory variables and the explained variable and the error terms are denoted by $U_{i t}$ and $\psi_{i t}$ respectively. Finally, the relation between the ECT and the explained variable is quantified by the coefficient $Y_{a, b i}$ for models $A$ and $B$, respectively. This coefficient will capture the long run causal relationship between the dependent variable and energy consumption. If it is significant in model $A$, the causality runs from GDP to energy use, whereas significance in model $B$ suggests reverse long run causality.

We can estimate these equations by means of ordinary least squares (OLS). ${ }^{12}$ From the significant coefficient on ECT in model A but not in model $B$ in table 4 it can be concluded that output (GDP) and capital formation (GFCF) share a long run cointegration relationship with energy usage (model $A$ ), but not vice versa (model $B$ ). Over the short run, the relation is bidirectional, as both the lagged GDP variable in Model A and the lagged energy variable in Model B appear to be significant in predicting future values of the dependent variable. This dynamic interaction is only valid for the very short run, as longer-term effects ( $t-2$ etc) are found to be insignificant.

\section{Panel vector error correction model results}

Model A: $\Delta \log (\mathrm{EC})$ explained by variable of interest (and controls):

\begin{tabular}{lcccc}
\hline Variable & time lag & Coefficient & t-statistic & Significance \\
\hline$\Delta \log (\mathrm{GDP})$ & $\mathrm{t}-1$ & 0.152 & 2.54 & ${ }^{\star \star \star}$ \\
$\mathrm{ECT}$ & $\mathrm{t}-1$ & -0.008 & -3.78 & \\
& & & & \\
& & & & \\
& Model B: $\Delta \log (\mathrm{GDP})$ & explained by & variable of interest & (and controls): \\
\hline Variable & time lag & Coefficient & $\mathrm{t}$-statistic & Significance \\
\hline$\Delta \log (\mathrm{EC})$ & $\mathrm{t}-1$ & 0.106 & 5.07 & \\
$\mathrm{ECT}$ & $\mathrm{t}-1$ & -0.001 & -0.79
\end{tabular}

* signals significance on a $10 \%$ level, ** $5 \%$ and *** $1 \%$

12 For model A lagged LEC was significant up to 3 lags (not reported below). In Model B only one lag was significant for GDP. Model A was therefore estimated using a sample size, $n=996$ observations, whereas Model $B$ was estimated with $n=1048$. Our results, however, do not depend on the sample size or number of lags included. 
In conclusion, our results strongly suggest that there is no evidence of a long run causal relationship from energy use to output in the OECD over the past 40 years. In the (very) short run the causality seems to run in both directions, but this makes perfect sense. In the period under investigation the OECD experienced several significant energy price hikes, causing a drop in energy use, followed by short run economic contractions. Over the longer run, however, such negative effects wear of rapidly and the long run causality runs from income to energy use. These results are in stark contrast to results reported in recent papers (published papers by Narayan and Smyth (2008), Lee and Chang (2008), Lee, Chang and Chen (2008) on the one hand and a working paper by Sinha (2009) on the other) using similar data and empirical methods in the literature. The following sections will first contrast our results to those reported by Lee, Chang and Chen (2008) and Narayan and Smyth (2008). Given the less than complete description of the analysis and results in Sinha's (2009) working paper, a final section is necessarily more speculative in contrasting our results to his.

\subsection{The importance of the error term specification}

Narayan and Smyth (2008) (NS) and Lee, Chang and Chen (2008) (LCC) are largely based on the same procedures and type of data, studying the G7 and 22 OECD countries for 3 and 4 decades, respectively. They concluded that energy, as well as capital, Granger cause output and that therefore energy should be seen as a vital input in the production function. Our analysis "nests" these earlier studies as our data has been broadened by including more countries (notably Czech Republic, Hungary, South Korea, Luxemburg, Mexico, Poland, Slovenia and Turkey) and controls for additional inputs (e.g. human capital). Excluding these variables, years and countries from the estimation and running our analysis in per worker terms as in Lee, Chang and Chen and Narayan and Smyth, however, does not affect our overall conclusion. ${ }^{13}$ Therefore our opposite conclusions probably follow from a different model specification. The Lee, Chang and Chen (2008) and Narayan and Smyth (2008) results

\footnotetext{
13 We use (first differences in the log) of gross fixed capital formation as our proxy for the capital stock as do NS, whereas LCC use (first differences in log of) capital stocks as constructed by Kamps (2006). This, however, is not likely to affect the results qualitatively. In a VECM specification the final regression is done in log first differences, i.e. in growth rates. And we feel it is reasonable to assume that the variation in growth rates of GFCF and the capital stock itself are highly correlated for countries close to their steady states. The standard neoclassical growth model predicts that in steady state all variables, including the capital stock, depreciation and net investment and gross fixed capital formation grow at the common rate of labour augmenting technical change. If we assume all OECD countries are close to their steady state, we know that the level of GFCF is close to the level of deprecation and consequently proportional to the capital stock if depreciation rates are more or less stable. These assumptions are not very strong for OECD countries. This makes it very unlikely that LCC come to opposite conclusions based on their different proxy for the capital stock.
} 
can be obtained in our data also by using their specification for the cointegration term, namely: ${ }^{14}$

$$
L G D P_{i t}=\alpha_{i}+\delta_{i} t+\beta_{1} L E C_{i t}+\beta_{2} L G F C F_{i t}+\varepsilon_{i t}
$$

If we use (2) instead of (1) in an Engle-Granger two-step procedural estimation, energy and capital inputs are found to Granger cause output over the long and short term in our data as well. The question is then, however, if these authors are justified in using (2) instead of (1). For this to be the case it must thus be shown that specification (2) is truly the long run equilibrium, or cointegration, relationship. NS and LCC offer theoretical arguments and references to earlier papers, but in the end assume this specification without testing for its appropriateness explicitly.

Table 5 Panel cointegration statistics

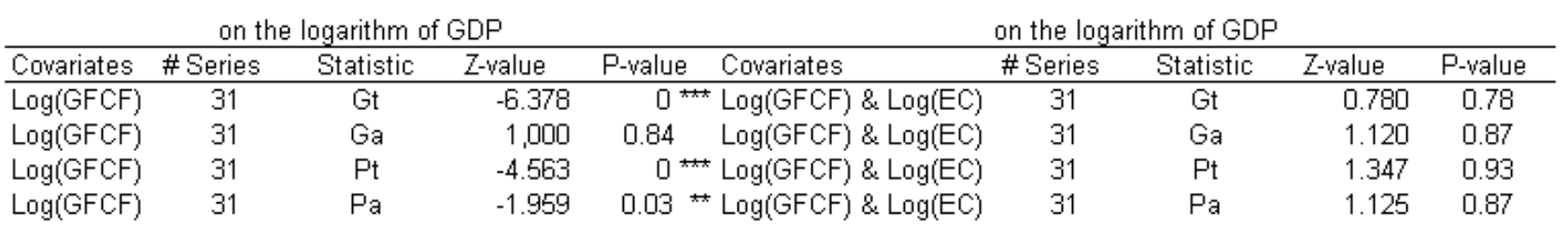

H0: no cointegration

* signals significance on a $10 \%$ level, $* * 5 \%$ and $* * * 1 \%$

Again the Westerlund panel cointegration test can be used. Table 5 presents panel cointegration tests on the logarithm of output for the covariates capital and for capital and energy together. Clearly, as one would expect from theory, LGFCF shares a long run relationship with LGDP and is highly significant in three out of the four tests, rejecting significance for only one member of the panel in the second test. However, as energy usage is added as a second covariate, the test results cannot reject the null that there is no covariation on the basis of the statistical outcome. These results justify energy use as a possible control variable, but not in the error correction term in a Granger causality cointegration framework. Our results show that (wrongly) adding energy consumption in the cointegration relationship leads to very different conclusions on the causal relationship of between energy and GDP. Assuming, on theoretical grounds, that energy is a factor of production thus leads to the conclusion that it indeed Granger-causes output. But if we allow the data to speak freely, the results are overturned.

\subsection{Adding Developing Countries and Omitting Capital}

14 NS are a bit implicit about the specification of their error correction term, but their equations (1) and (2) suggest they use a specification similar to that in LCC. 
The analysis in Sinha (2009) is presented in such a way that it is hard to reproduce in our data. In his paper Sinha does state that for the 30 OECD countries in his sample results are "quite similar" to those for the entire sample, that is, he finds a significant long run relationship in both directions. When we redo our analysis, restricting our sample from 1975 to 2000, we do not find this reverse causality, suggesting our model specifications (or data) must differ. An obvious difference in the two papers is the fact that we follow Narayan and Smyth (2008) in controlling for capital (proxied by gross fixed capital formation). Given that capital is typically complementary to energy use and OECD countries are highly capital intensive, the omission of this variable will bias Sinha's results. Sinha (2009) probably did not include this variable because such data are notoriously hard to come by for developing countries. Dropping capital from our analysis, however, does not change our results qualitatively. Again, it seems, the specification of the error correction term is the main culprit, although we cannot be certain, as Sinha (2009) is not explicit about his specification.

Another explanation suggests itself, however. Taking 58 developing countries increases the weight of developing countries in the panel along two dimensions. It shortens the time dimension and broadens the cross-section. The available evidence on developing countries only (e.g. Lee (2005)) suggests that for developing countries the causation may well run the other way in the long run. Given their largely resource and agriculture driven economies, developing countries may experience growth only if energy use can first increase to build up the manufacturing sector and industrial infrastructures. Adding 58 such countries (without adjusting for their much smaller share in global GDP and energy use) can then "bias" the results towards finding bidirectional causality as well. This suggests a multi-regime modelling approach would be more appropriate in such broad panels.

\subsection{Summary}

The results of our vector error correction model clearly show strong unidirectional causality from GDP and capital formation to energy use, as the cointegration term is significant at the $1 \%$ level in model $A$ and not at all in model $B$. However, model $B$ confirms that there are some short run influences of energy use running in the opposite direction. Contrasting our results to those found by other authors we conclude that the differences are probably caused by our specification of the error correction term. We can only be sure, however, if we exactly reproduce their results using their data, which we do not have. Tests in our data, however, show that our specification is the one the properties of the data would suggest, also if we limit our 
panel to the dimensions and variables used in the other studies. Furthermore we argue that excluding capital and including developing countries without properly weighing them may well have biased results in earlier studies towards finding evidence for a causal link from energy use to GDP.

\section{Conclusion}

We show that in the OECD Granger causality runs from output growth and capital formation, or broadly stated 'economic activity' to energy use, and not the other way around. Energy can therefore not be seen as a vital input into the production function complementing capital and labour. This results stands in direct opposition to results found earlier in the literature. As we have shown, however, those results were obtained under the assumption that energy is an input in the production function. Testing for the appropriate specification of the long run relationship between energy use and GDP, suggests the error correction term should not be specified as suggested by the KLEMs-production function. More empirical research is urgently needed to establish this result more robustly. Quick wins would be to provide specification tests for the Lee, Chang and Chen (2008) and Narayan and Smyth (2008) datasets. It would furthermore be interesting to collect capital stock data on developing countries to extend the panel, including the important capital stock proxy, to developing countries.

The issue at hand is of key importance. Policies aiming at reducing either industrial or residential demand for energy can therefore only be expected to have a small shortrun detrimental effect on overall economic activity. Additionally, the fear that prolonging the Kyoto protocol might negatively influence global economic recovery is unfounded if our results are found to be robust. When energy use is not a vital input in the production function, recovery policies should focus on capital, labour and productivity inputs (education and R\&D etc.) and there is no reason why a reduction of greenhouse gas emissions by increasing energy prices, pricing carbon emissions or implementing energy efficiency measures, should cause a fall in output over the longer term. However, as stated, there may be a short lived and short run negative effect, validating the argument that the implementation of these policies in the worst part of the downturn of the business cycle may not be the optimal solution. Starting negotiations now to have policies in place in a few years, however, seems like a good prospect for both the environment and the economy. 


\section{References}

Al-Iriani, M.A. (2005). Energy-GDP relationship revisited: AN example from GCC countries using panel causality, Energy Policy, 34, pp. 3342-3350.

Asafu-Adjaye, J. (2000). The relationship between energy consumption, energy prices and economic growth: Time series evidence from Asian developing countries. Energy Economics, 22, pp. 615-625.

Barro, R.J. and J.W. Lee (2001). Schooling quality in a cross-section of countries. Economica, 68(272), pp $465-488$.

Dickey, D.A. and W. A. Fuller (1979). Distribution of the estimators for autoregressive time series with a unit root. Journal of the American statistical association.

Energy Information Administration (2006). International Energy Annual 2006. Washington D.C..

Engle, R.F. and C.W.J. Granger (1987). Co-Integration and Error Correction: Representation, Estimation, and Testing. Econometrica, Vol. 55, No. 2, pp. 251-276.

Erol, U., and E.S.H. Yu (1987). On the causal relationship between energy and income for industrialized countries. Journal of Energy and Development, 13, pp. 113-122.

Granger, C. W. J. (1988) Causality, cointegration, and control. Journal of Economic Dynamics and Control, 12(2-3), pp 551-559.

Granger, C.W.J. and J.L. Lin (1995) Causality in the Long Run. Econometric Theory, 11(3), pp. 530-536.

Ghali, K.H., and M.I.T. El-Sakka (2004). Energy use and output growth in Canada: A multivariate cointegration analysis. Energy Economics, 26(2), pp. 225-238.

Glasure, Y. U. (2002). Energy and national income in Korea: Further evidence on the role of omitted variables. Energy Economics, 24, pp.355-365.

Glasure, Y. U., and A.R. Lee (1997). Cointegration, error-correction, and the relationship between GDP and energy: The case of South Korea and Singapore. Resource and Energy Economics, 20, pp. 17-25.

Im, K.S., M.H. Pesaran and Y. Shin (2003) Testing for Unit Roots in Heterogeneous Panels. Journal of Econometrics, 115, pp. 53-74.

Johansen, S. (1991). Estimation and hypothesis testing of cointegration vectors in Gaussian vector autoregressive models. Econometrica, 59, 1551-1580.

Kraft, J., and A. Kraft (1978). On the relationship between energy and GNP, Journal of Energy and Development. 3, pp. 401-403.

Levin, A., C.F. Lin and C.S.J. Chu (2002) Unit Root Tests in Panel Data: Asymptotic and Finite Sample Properties. Journal of Econometrics, 108, pp. 1-24.

Lee, C.C. (2005). Energy consumption and GDP in developing countries: A cointegrated panel analysis. Energy Economics, 27, pp. 415-427.

Lee, C.C. (2006). The causality relationship between energy consumption and GDP in G-11 countries revisited. Energy Policy, 34, 1086-1093.

Lee, C.C. and C.P. Chang (2008) Energy consumption and economic growth in Asian economies: A more comprehensive analysis using panel data, Resource and Energy Economics, 30, pp. 50-65.

Lee, C.C., C.P. Chang and P.F. Chen (2008) Energy-income causality in OECD countries revisited: The key role of capital stock, Energy Economics, 30, pp. 23592373.

Mehrara, M. (2007) Energy consumption and economic growth: the case of oil exporting countries, Energy Policy, 35, pp. 2939-2945. 
Maddala, G.S. and S. Wu (1999). A Comparative Study of Unit Root Tests with Panel Data and a New Simple Test. Oxford Bulletin of Economics and Statistics, 61, pp. 631652.

Mahadevan, R. and J. Asafu-Adjaye (2007) Energy consumption, economic growth and prices: A reassessment using panel VECM for developed and developing countries, Energy Policy, 35(4), pp. 2481-2490.

Masih, A.M.M., and R. Masih (1996). Energy consumption, real income and temporal causality: Results from a multi-country study based on cointegration and errorcorrection modeling techniques. Energy Economics, 18, pp. 165-183.

Masih, A.M.M., and R. Masih (1998). A multivariate cointegrated modeling approach in testing temporal causality between energy consumption, real income and prices with an application to two Asian LDCs. Applied Economics, 30, pp. 1287-1298.

Narayan, P.K. and R. Smyth (2008). Energy consumption and real GDP in G7 countries: New evidence from panel cointegration with structural breaks, Energy Economics, 30 pp. 2331 - 2341.

Persyn, D. and J. Westerlund (2008) Error-correction-based cointegration tests for panel data. The Stata Journal, 8(2), pp. 232-241.

Sinha, D. (2009). The energy consumption-GDP nexus: Panel data evidence from 88 countries. MPRA working paper, 18446.

Soytas, U., and R. Sari (2003). Energy consumption and GDP: Causality relationship in G-7 countries and emerging markets. Energy Economics, 25, 33-37.

Soytas, U., and R. Sari (2006). Energy consumption and income in G-7 countries, Journal of Policy Modeling, 28(7), pp. 739-750.

Stern, D. I. (2000). A multivariate cointegration analysis of the role of energy in the US economy. Energy Economics, 22, pp. 267-283.

Westerlund, J. (2006). Testing for panel cointegration with multiple structural breaks. Oxford Bulletin of Economics and Statistics, 68, pp. 101-132.

Westerlund, J. (2007). Testing for Error Correction in Panel Data, Oxford Bulletin of Economics and Statistics, 69(6), pp. 709 - 748.

Yu, E.S.H., and B.K. Hwang (1984). The relationship between energy and GNP:

Further results. Energy Economics, 6, pp. 186-190.

Yu, E.S.H., and J.C. Jin (1992). Cointegration tests of energy consumption, income, and employment. Resources and Energy, 14, pp. 259-266.

\section{Acknowledgements STATA modules}

Levinlin and Ipshin test: F. Bornhorst, European University Institute, Italy and C. F. Baum, Boston College, Boston MA, USA.

Xtfisher: Scott Merryman, Risk Management Agency, US Dept. of Agriculture, Washingthon DC, USA. 
Appendix A - Descriptive Statistics over the country dimension

\begin{tabular}{|c|c|c|c|c|c|c|c|c|c|c|c|c|}
\hline \multirow[t]{2}{*}{ Country } & \multicolumn{3}{|c|}{$\begin{array}{l}\text { Gross Domsetic Product } \\
\text { in PPP per capita }\end{array}$} & \multicolumn{3}{|c|}{ Employment } & \multicolumn{3}{|c|}{$\begin{array}{c}\text { Gross Fixed Capital Formation } \\
\text { in billions of } 2000 \text { USD }\end{array}$} & \multicolumn{3}{|c|}{$\begin{array}{l}\text { Energy consumption } \\
\text { in } \mathrm{kWH} \text { per capita }\end{array}$} \\
\hline & mean & st.dev. & median & mean & st.dev. & median & mean & st.dev. & median & mean & st.dev. & median \\
\hline Australia & 16810 & 3995 & 16497 & 6454 & 1410 & 6356 & 49,45 & 20,41 & 44,74 & 5845 & 2612 & 5914 \\
\hline Austria & 15785 & 4876 & 16402 & 3262 & 270 & 3191 & 27,55 & 9,64 & 26,31 & 4468 & 1627 & 4697 \\
\hline Belgium & 16366 & 4769 & 17080 & 3734 & 108 & 3724 & 29,24 & 8,90 & 27,46 & 4786 & 2021 & 4908 \\
\hline Canada & 18500 & 4431 & 19231 & 10466 & 2653 & 11019 & 75,43 & 30,00 & 74,88 & 12231 & 3905 & 12804 \\
\hline Czech Republic & 10662 & 1907 & 11384 & 5032 & 153 & 5037 & 10,26 & 3,25 & 10,27 & 4878 & 687 & 5057 \\
\hline Denmark & 18268 & 3941 & 18177 & 2451 & 190 & 2420 & 17,15 & 6,13 & 15,72 & 4300 & 1833 & 4590 \\
\hline Finland & 14853 & 4594 & 15350 & 2265 & 132 & 2233 & 16,75 & 4,51 & 17,05 & 8342 & 4292 & 8295 \\
\hline France & 15566 & 4180 & 16145 & 21677 & 1188 & 21823 & 164,40 & 44,20 & 164,30 & 4337 & 1899 & 4417 \\
\hline Germany & 16196 & 4325 & 16587 & 29101 & 4251 & 26829 & 266,60 & 70,55 & 255,00 & 4966 & 1795 & 5796 \\
\hline Greece & 10498 & 2928 & 11684 & 3480 & 278 & 3424 & 16,73 & 4,91 & 17,33 & 2192 & 1302 & 2247 \\
\hline Hungary & 7642 & 2309 & 8486 & 3778 & 139 & 3752 & 6,71 & 2,22 & 7,44 & 2623 & 755 & 2900 \\
\hline Iceland & 17664 & 5455 & 19430 & 108 & 27 & 106 & 1,02 & 0,37 & 1,03 & 11697 & 6410 & 12689 \\
\hline Ireland & 11780 & 5490 & 10707 & 1155 & 144 & 1111 & 8,57 & 4,51 & 8,19 & 2834 & 1390 & 2836 \\
\hline Italy & 14731 & 4495 & 15332 & 20579 & 644 & 20590 & 147,60 & 39,69 & 148,70 & 3031 & 1227 & 3096 \\
\hline Japan & 15631 & 6308 & 15659 & 55771 & 6699 & 55360 & 767,00 & 368,30 & 772,90 & 4745 & 2162 & 4717 \\
\hline Korea & 5551 & 3854 & 4283 & 14365 & 4394 & 14201 & 55,08 & 56,97 & 32,36 & 2131 & 1747 & 1409 \\
\hline Luxembourg & 21822 & 8544 & 18592 & 168 & 36 & 158 & 1,97 & 0,89 & 1,59 & 11392 & 2697 & 11648 \\
\hline Mexico & 6242 & 1253 & 6742 & 30175 & 7215 & 32159 & 58,29 & 28,22 & 57,14 & 1114 & 355 & 1117 \\
\hline Netherlands & 16442 & 4175 & 16477 & 5476 & 1043 & 5055 & 47,33 & 14,20 & 43,03 & 4053 & 1506 & 4293 \\
\hline New Zealand & 14976 & 1873 & 15017 & 1323 & 287 & 1274 & 6,00 & 2,10 & 6,02 & 6282 & 2122 & 6292 \\
\hline Norway & 16143 & 5648 & 16366 & 1841 & 267 & 1908 & 20,71 & 6,21 & 22,26 & 18257 & 5480 & 18860 \\
\hline Poland & 6229 & 1270 & 6346 & 15529 & 1466 & 15450 & 12,37 & 10,35 & 9,24 & 2539 & 833 & 2961 \\
\hline Portugal & 9342 & 3648 & 9242 & 4000 & 504 & 4013 & 14,08 & 6,42 & 12,70 & 1702 & 1087 & 1558 \\
\hline Slovak Republic & 8769 & 805 & 8608 & 2181 & 50 & 2166 & 4,93 & 1,87 & 4,81 & 4286 & 795 & 4490 \\
\hline Spain & 11244 & 3508 & 11142 & 12666 & 839 & 12580 & 75,11 & 29,60 & 67,69 & 2520 & 1299 & 2643 \\
\hline Sweden & 16395 & 3508 & 16550 & 4018 & 250 & 3986 & 29,05 & 6,54 & 28,02 & 11011 & 4226 & 10703 \\
\hline Switserland & 22533 & 3408 & 22919 & 3387 & 410 & 3256 & 38,24 & 9,69 & 36,82 & 5686 & 1612 & 5931 \\
\hline Turkey & 4297 & 1147 & 4253 & 16541 & 3232 & 16280 & 26,18 & 14,00 & 23,51 & 598 & 434 & 490 \\
\hline United Kingdom & 14357 & 3465 & 13750 & 25180 & 839 & 25014 & 142,40 & 46,60 & 126,10 & 4564 & 944 & 4669 \\
\hline United States & 21516 & 5398 & 20955 & 99982 & 21602 & 100907 & 872,50 & 397,90 & 795,10 & 9331 & 2908 & 9698 \\
\hline
\end{tabular}




\begin{tabular}{|c|c|c|c|c|c|c|c|c|c|c|c|c|}
\hline \multirow[t]{2}{*}{ Year } & \multicolumn{3}{|c|}{$\begin{array}{l}\text { Gross Domsetic Product } \\
\text { in PPP per capita }\end{array}$} & \multicolumn{3}{|c|}{$\begin{array}{c}\text { Employment } \\
\text { in thousands of jobs }\end{array}$} & \multicolumn{3}{|c|}{$\begin{array}{l}\text { Gross Fixed Capital Formation } \\
\text { in billions of } 2000 \text { USD }\end{array}$} & \multicolumn{3}{|c|}{$\begin{array}{l}\text { Energy consumption } \\
\text { in } \mathrm{KWH} \text { per capita }\end{array}$} \\
\hline & mean & st. dev. & median & mean & st. dev. & median & mean & st.dev. & median & mean & st.dev. & median \\
\hline 1960 & 7581 & 3370 & 7800 & 11263 & 15893 & 3599 & 49,73 & 99,25 & 11,63 & 2128 & 1794 & 1587 \\
\hline 1961 & 7865 & 3419 & 8192 & 11352 & 15964 & 3633 & 52,45 & 102,80 & 12,12 & 2259 & 1891 & 1659 \\
\hline 1962 & 8134 & 3488 & 8429 & 11463 & 16178 & 3657 & 56,24 & 109,80 & 12,88 & 2421 & 2057 & 1774 \\
\hline 1963 & 8439 & 3543 & 8708 & 11399 & 16044 & 4028 & 60,38 & 117,70 & 13,76 & 2617 & 2223 & 1903 \\
\hline 1964 & 8872 & 3712 & 9132 & 11540 & 16324 & 4127 & 64,73 & 126,20 & 14,61 & 2864 & 2504 & 2069 \\
\hline 1965 & 9187 & 3818 & 9475 & 11692 & 16635 & 4166 & 67,67 & 133,20 & 15,19 & 2972 & 2642 & 2161 \\
\hline 1966 & 9500 & 3868 & 9772 & 11858 & 17001 & 4191 & 72,10 & 141,00 & 16,16 & 3122 & 2719 & 2263 \\
\hline 1967 & 9731 & 3848 & 10151 & 11963 & 17280 & 4177 & 75,77 & 146,10 & 16,96 & 3262 & 2796 & 2367 \\
\hline 1968 & 10086 & 3895 & 10452 & 12094 & 17580 & 4205 & 81,15 & 156,30 & 17,73 & 3471 & 2953 & 2604 \\
\hline 1969 & 10614 & 4086 & 10955 & 12253 & 17918 & 4260 & 86,73 & 166,50 & 18,63 & 3734 & 3026 & 2843 \\
\hline 1970 & 11012 & 4163 & 11550 & 12388 & 17714 & 4790 & 90,97 & 174,50 & 19,50 & 4081 & 3123 & 3041 \\
\hline 1971 & 11236 & 4219 & 11814 & 12471 & 18162 & 4336 & 95,35 & 183,30 & 22,18 & 3998 & 3244 & 3221 \\
\hline 1972 & 11724 & 4310 & 12379 & 12634 & 18561 & 4320 & 102,10 & 198,00 & 24,45 & 4244 & 3329 & 3414 \\
\hline 1973 & 12313 & 4461 & 13049 & 12935 & 19135 & 4329 & 109,50 & 213,00 & 24,96 & 4566 & 3571 & 3631 \\
\hline 1974 & 12524 & 4488 & 13245 & 13091 & 19361 & 4372 & 105,50 & 202,00 & 25,96 & 4711 & 3747 & 3778 \\
\hline 1975 & 12458 & 4251 & 13361 & 12725 & 18866 & 4743 & 101,30 & 192,40 & 24,67 & 4640 & 3552 & 3775 \\
\hline 1976 & 12861 & 4367 & 13673 & 12897 & 19338 & 4755 & 104,80 & 199,90 & 25,61 & 4935 & 3720 & 4078 \\
\hline 1977 & 13146 & 4427 & 14067 & 13114 & 19902 & 4801 & 109,20 & 210,60 & 27,80 & 5043 & 3680 & 4148 \\
\hline 1978 & 13486 & 4544 & 14356 & 13364 & 20590 & 4859 & 115,60 & 225,70 & 26,05 & 5262 & 3814 & 4346 \\
\hline 1979 & 13860 & 4698 & 14847 & 13589 & 21085 & 4927 & 121,20 & 236,90 & 27,64 & 5508 & 4040 & 4542 \\
\hline 1980 & 14074 & 4811 & 15350 & 13968 & 20860 & 5094 & 121,70 & 234,90 & 28,64 & 5615 & 4078 & 4599 \\
\hline 1981 & 14138 & 4863 & 15613 & 13748 & 21394 & 5118 & 120,90 & 233,80 & 27,17 & 5714 & 4229 & 4590 \\
\hline 1982 & 14165 & 4799 & 16012 & 13698 & 21287 & 5119 & 117,10 & 225,50 & 26,31 & 5766 & 4265 & 4676 \\
\hline 1983 & 14366 & 4878 & 16353 & 13770 & 21558 & 5055 & 117,50 & 228,20 & 26,20 & 5991 & 4504 & 4740 \\
\hline 1984 & 14823 & 5111 & 16822 & 13970 & 22250 & 5084 & 123,20 & 243,20 & 26,21 & 6307 & 4816 & 4959 \\
\hline 1985 & 15206 & 5274 & 17108 & 14149 & 22624 & 5178 & 129,00 & 256,00 & 27,83 & 6532 & 4941 & 5258 \\
\hline 1986 & 15596 & 5445 & 17437 & 14380 & 23055 & 5225 & 133,70 & 264,90 & 28,67 & 6652 & 4936 & 5328 \\
\hline 1987 & 16000 & 5524 & 17790 & 14654 & 23557 & 5243 & 139,90 & 275,40 & 30,32 & 6872 & 5057 & 5548 \\
\hline 1988 & 16511 & 5697 & 18342 & 14922 & 24043 & 5251 & 151,10 & 297,20 & 33,13 & 7100 & 5209 & 5725 \\
\hline 1989 & 17003 & 5915 & 19142 & 15213 & 24537 & 5245 & 161,00 & 315,80 & 37,02 & 7225 & 5170 & 5856 \\
\hline 1990 & 17241 & 6017 & 19506 & 15722 & 24461 & 5676 & 168,20 & 330,20 & 40,20 & 7320 & 5197 & 5947 \\
\hline 1991 & 17158 & 6188 & 19333 & 16198 & 24676 & 5670 & 168,10 & 330,80 & 37,96 & 7401 & 5256 & 6222 \\
\hline 1992 & 17217 & 6246 & 19173 & 15810 & 24500 & 4883 & 168,80 & 332,70 & 38,06 & 7359 & 5179 & 6162 \\
\hline 1993 & 17311 & 6349 & 18710 & 15757 & 24767 & 4874 & 166,20 & 329,60 & 37,97 & 7424 & 5251 & 6098 \\
\hline 1994 & 17788 & 6513 & 19343 & 15520 & 24904 & 4685 & 171,60 & 339,10 & 39,39 & 7601 & 5314 & 6149 \\
\hline 1995 & 18221 & 6547 & 19952 & 15672 & 25167 & 4688 & 177,30 & 350,90 & 39,72 & 7779 & 5375 & 6312 \\
\hline 1996 & 18670 & 6614 & 20136 & 15868 & 25480 & 4708 & 186,00 & 369,60 & 41,58 & 7888 & 5261 & 6406 \\
\hline 1997 & 19307 & 6880 & 20697 & 16129 & 25998 & 4733 & 194,20 & 385,40 & 42,85 & 8064 & 5406 & 6427 \\
\hline 1998 & 19841 & 7166 & 21328 & 16310 & 26277 & 4871 & 201,20 & 400,40 & 44,38 & 8273 & 5700 & 6481 \\
\hline 1999 & 20430 & 7421 & 22206 & 16474 & 26556 & 4852 & 211,30 & 423,40 & 46,23 & 8467 & 5891 & 6480 \\
\hline 2000 & 21174 & 7731 & 22974 & 22747 & 42769 & 5041 & 221,50 & 443,60 & 48,32 & 8715 & 6057 & 6560 \\
\hline
\end{tabular}

